\title{
Pattern and Distribution of Primary Bone Tumours in Jos Nigeria
}

\author{
Ode M.B ${ }^{1}$, Misauno M.A ${ }^{2}$, Nwadiaro H.C ${ }^{3}$, Onche I.I ${ }^{1}$, Shitta A.H ${ }^{2}$, \\ Amupitan $\mathrm{I}^{1}$ \\ ${ }^{1}$ Department of Orthopaedics and Trauma, University of Jos/Jos university teaching hospital. \\ ${ }^{2}$ Department of Surgery, University of Jos/Jos university teaching hospital. \\ ${ }^{3}$ Department of Orthopaedics and Trauma, University of Abuja Teaching hospital Gwagwalada.
}

\begin{abstract}
Bone tumours have been noticed to be on the increase Africa. The incidence of these tumours initially thought, to be uncommon in our environment has been on the rise. These tumours like those in any other part of the body are better managed with early diagnosis and subsequent treatment. The study was aimed at determining the pattern of presentation of bone tumours, with a view to determining the commonest types, the most involved sites of the body and the age of presentation of these tumuors. This was a retrospective study carried out at the Jos university teaching hospital. The study covered a period of ten years from 2000 to 2010. From the cancer registry at the hospital, and case folders of the patients information of patients as regards the histological type of the bone tumour, the age and sex of the patients and the site of involvement were obtained.A Total of 103 bone tumours were seen over the study period. The mean age of presentation was 29.4yearst/16.9 years with an age range of 3 to 75 years. Benign bone tumoursaccounted for67(66.3\%) of the tumours while malignant tumours were $36(33.7 \%)$ of the tumours.The benign tumours consisted of,osteochondroma 12(17.9\%), Giant cell tumour 12(17.9\%), fibrous histiocytoma 11(16.4\%) and osteoid osteoma7 (12\%), while the malignant variety were osteosarcoma 17(50\%),fibrosarcoma 10(29.4\%) andChondrosarcoma 4 (11\%) . The anatomical regional location of the benigntumourswere; tibia 13(19.4\%), femur 13 (19.4\%). While that of the malignant variety were; femur 10(29.4\%), tibia 9(26.4\%). Benign bone tumours make up about two thirds of the bone tumours in our environment while the rest are malignant, with osteochondroma and giant cell tuomours making up the bulk of the benign tumours and osteosarcoma the most common malignant type. The femur and the tibia were the sites mostly affected by bone tumours.
\end{abstract}

Keywords: Bonetumours, Distribution, Nigeria, Primary.

\section{Introduction.}

Bone tumours have been identified to be on the rise in Africa and other parts of the world(1-3). In these parts of the world where a large part of the health budget is targeted towards the prevention and care of infectious disease, not much emphasis is given to the management of tumours. In such an environment with limited health care resources and poor health seeking behavior of the populace mainly from ignorance, poverty and cultural beliefs, (4) there is the tendency for delayed presentation in patients with tumours.(5, 6). Some bone tumours have typical pattern of occurrences, well described clinical courses as well as clear treatment protocols with satisfactory outcomes. Knowledge of the pattern of occurrences of bone tumours would serve as a guide to be used in clinical evaluation of patients. Bone tumours as with tumours in other parts of the body have better prognosis with early diagnosis and treatment. $(5,7)$ This information would also aid in public awareness to the population on the presence and the occurrences of such conditions in our environment as a tool to encourage prompt hospital presentation and improve the stage of presentation of these tumours. The limited health resources for the care of bone tumours can thus be channeled in a more targeted fashion towards their management. Majority of Primary bone tumours have been found benign rather than malignant $(8,9)$. This in our setting tends to delay the presentation as patients assume the tumours to be benign only presenting when the shear size of the tumour impairs functionality and is cosmetically unappealing(10). This study was aimed at determining the pattern of presentation of bone tumours, with a view to determining the commonest types, the most involved sites of the body and the age of presentation of these tumuors.

\section{Materials And Methods}

This was a retrospective study carried out at the Jos university teaching hospital from January 2001 to December 2010.Data was obtained from the cancer registry at the hospital, and case folders of the patients. . Patient's case notes with incomplete data entries were excluded from the study. Information of patients as regards the histological type of the bone tumour, the age and sex of the patients and the site of involvement were obtained. The data was analyzed for simple means and percentages using Epi-Info statistical software. 


\section{Results}

A Total of 103 bone tumours were seen over the study period. The mean age of presentation was $29.4 \mathrm{yrs}+/-16.9$ with age range of 3years to $75 y e a r s$.

Benign bone tumours accounted for $67(66.3 \%)$ of the tumours while malignant tumourswere $36(33.7 \%)$ of the tumours. The benign tumours consisted of osteochondroma 12(17.9\%), Giant cell tumour $12(17.9 \%)$, fibrous histiocytoma 11(16.4\%) and osteoid osteoma7 (12\%) Table 1, while the malignant variety were osteosarcoma 17(50\%), fibrosarcoma10(29.4\%) and Chondrosarcoma $4(11 \%)$ Table 2.The anatomical regional location of, the benign tumourswere ; tibia $13(19.4 \%)$ femur $13(19.4 \%)$ while that of the malignant tumours were; femur 10(29.4\%), tibia 9(26.4\%). Tables 3 and 4

\section{Tables}

TABLE 1 Benign bone tumours

\begin{tabular}{|l|l|l|}
\hline Histologic variety & Number & Percentage(\%) \\
Osteochondroma & 12 & 17.9 \\
Giant cell tumour & 12 & 17.9 \\
Fibrous histiocytoma & 11 & 16.4 \\
Osteoid osteoma & 7 & 12.0 \\
Hemangiopericytoma & 5 & 8.0 \\
Chondroma & 5 & 8.0 \\
Ossifying fibroma & 3 & 5.0 \\
osteofibroma & 3 & 5.0 \\
Fibrous dysplasia & 3 & 5.0 \\
Chondromyxoid fibroma & 2 & 3.0 \\
Enchondroma & 1 & 2.0 \\
chondroblastoma & 1 & \\
& & $\mathbf{1 0 0}$ \\
Total & $\mathbf{6 7}$ & \\
\hline
\end{tabular}

TABLE 2 Malignant bone tumours

\begin{tabular}{|l|l|l|}
\hline Histologic variety & Number & Percentage(\%) \\
Osteosarcoma & 17 & 50 \\
Fibrosarcoma & 10 & 28 \\
Chondrosarcoma & 4 & 11 \\
Plasmacytoma & 2 & 6 \\
Malignant fibrous histiocytoma & 2 & 6 \\
Ewings sarcoma & 1 & 2 \\
Total & $\mathbf{3 6}$ & $\mathbf{1 0 0}$ \\
\hline
\end{tabular}

TABLE 3 Anatomic location of benign tumours

\begin{tabular}{|l|l|l|}
\hline Site of tumour & Number & Percentage(\%) \\
Tibia & 18 & 26.7 \\
Femur & 18 & 26.7 \\
Phalanges & 10 & 14.9 \\
Clavicle & 7 & 10.4 \\
Pelvis & 5 & 7.6 \\
Humerus & 3 & 4.6 \\
Rib & 2 & 3.0 \\
Ulna & 2 & 3.0 \\
Metatarsal & 2 & 3.0 \\
Total & $\mathbf{6 7}$ & $\mathbf{1 0 0}$ \\
\hline
\end{tabular}

TABLE 4 Anatomic location of malignant tumours

\begin{tabular}{|l|l|l|}
\hline Site of tumour & Number & Percentage(\%) \\
Femur & 11 & 30.6 \\
Tibia & 9 & 25.0 \\
Pelvis & 5 & 13.9 \\
Humerus & 3 & 8.3 \\
Scapula & 2 & 5.6 \\
Metatarsal & 2 & 5.6 \\
Phalanges & 1 & 2.8 \\
Clavicle & 1 & 2.8 \\
Rib & 1 & 2.8 \\
Metacarpal & 1 & 2.8 \\
Total & $\mathbf{3 6}$ & $\mathbf{1 0 0}$ \\
\hline
\end{tabular}




\section{Discussion}

This study revealed that benign tumours made up two thirds(66.3\%) of the primary tumours affecting the bone. This is in agreement with the study by Abdulkareem(11) where bening bone tumours made up about two thirds of all bone tumours. The commonesthistologicalpathological variety of benign bone tumours in this study wereosteochondroma (17.9\%)and giant cell tumours (17.9\%). Studies by Mohammed et al(12)from north western Nigeria andAbdulkarrem et al(11)from south western Nigeria, also showed these as being the commonest variant of benign bone tumours.It can be assumed then that this may be the pattern throughout the country .Herget et al(13) also found osteochondroma as the commonest benign bone tumour in Germany. These tumours typically affect individuals in the second and third decades of life, may thus occur as the predominant variety in Nigeria which has a life expectancy of approximately 47 years(14). The bulk of the population thus falling within the second and third decades of life may account for the preponderance of these benign tumours.The malignant bone tumours make up a third of the primary bone tumours with the most prevalent histological variant being osteosarcoma.This finding is similar to those in studies carried out by Mohammed et al.(12) Ferreira et al(5)Kalra et al and Duonget al(15).Osteosarcoma is also a tumour whichcommonly occurs in the second and third decades $(16,17)$ except for the variety in the elderly that is secondary to Paget's disease which is rare in Africa(18). The preponderance of this tumour may not be unconnected with the large proportion of the Nigerian population within this age bracket also. A case of Ewing's sarcoma was discovered in this study which is noteworthy as this malignant tumour is believed to be rare in Africa(19).

The tibia and the femur were noted to be the commonest sites of occurrence of tumoursin both the malignant and benign groups.Gouin and colleagues(20) also had similar findingsas well as Arora et al(17)This is may be explained by the fact that the commonest tumours in both the benign and malignant groups (osteochondroma, giant cell tumour and osteosarcoma) have a predilection for these sites. There was a wide range of presentation of these tumours 3yrs to $75 \mathrm{yrs}$ showing that all age groups are susceptible to bone tumours. There is a need to carry out a multi centered prospective similar study in the future as the quality of health care gradually improves with a concomitant increase in the life expectancy of the population, to see if there is a change in the distribution of primary bone tumours in our environment which will also aid in targeting the scarce healthresources towards the management of these tumours.

\section{Conclusion}

Benign bone tumours make up about two thirds of the bone tumours in our environment while the rest are malignant, with osteochondroma and giant cell tumours making up the bulk of the benign tumours and osteosarcoma the most common malignant type. The femur and the tibia were the sites mostly affected by bone tumours.

\section{References}

[1]. Obalum DC, Eyesan SU, Ogo CN, Enweluzo GO. Multicentre study of bone tumours. The Nigerian postgraduate medical journal. 2010;17(1):23-6.

[2]. Omololu AB, Okolo CA, Ogunlade SO, Oyebadejo TY, Adeoye AO, Ogunbiyi JO, et al. Primary malignant bone tumours in Ibadan, Nigeria: an update. African journal of medicine and medical sciences. 2009;38(1):77-81.

[3]. Pearce MS, Parker L, Windebank KP, Cotterill SJ, Craft AW. Cancer in adolescents and young adults aged 15-24 years: a report from the North of England young person's malignant disease registry, UK. Pediatric blood \& cancer. 2005;45(5):687-93.

[4]. Eyesan SU, Obalum DC, Nnodu OE, Abdulkareem FB, Ladejobi AO. Challenges in the diagnosis and management of musculoskeletal tumours in Nigeria. International orthopaedics. 2009;33(1):211-3.

[5]. Ferreira N, Marais LC. Osteosarcoma presentation stages at a tumour unit in South Africa. South African medical journal = SuidAfrikaanse tydskrif vir geneeskunde. 2012;102(8):673-6.

[6]. Madu AJ, Ocheni S, Nwagha TA, Ibegbulam OG, Anike US. Multiple myeloma in Nigeria: an insight to the clinical, laboratory features, and outcomes. Nigerian journal of clinical practice. 2014;17(2):212-7.

[7]. Brown BJ, Bamgboye EA, Sodeinde O. Causes of death in childhood cancer at the Department of Paediatrics, University College Hospital, Ibadan. African journal of medicine and medical sciences. 2008;37(1):7-13.

[8]. Lasebikan OA, Nwadinigwe CU, Onyegbule EC. Pattern of bone tumours seen in a regional orthopaedic hospital in Nigeria. Nigerian journal of medicine : journal of the National Association of Resident Doctors of Nigeria. 2014;23(1):46-50.

[9]. Obalum DC, Giwa SO, Banjo AF, Akinsulire AT. Primary bone tumours in a tertiary hospital in Nigeria: 25 year review. Nigerian journal of clinical practice. 2009;12(2):169-72.

[10]. Obalum DC, Eyesan SU, Ezembakwe ME, Abdulkareem FB. Pattern of osteochondromas in Lagos, Nigeria. Nigerian quarterly journal of hospital medicine. 2008;18(2):69-71.

[11]. Abdulkareem FB, Eyesan SU, Akinde OR, Ezembakwe ME, Nnodu OE. Pathological study of bone tumours at the National Orthopaedic Hospital, Lagos, Nigeria. West African journal of medicine. 2007;26(4):306-11.

[12]. Mohammed A, Isa HA. Pattern of primary tumours and tumour-like lesions of bone in Zaria, northern Nigeria: a review of 127 cases. West African journal of medicine. 2007;26(1):37-41.

[13]. Herget GW, Kontny U, Saueressig U, Baumhoer D, Hauschild O, Elger T, et al. [Osteochondroma and multiple osteochondromas: recommendations on the diagnostics and follow-up with special consideration to the occurrence of secondary chondrosarcoma]. Der Radiologe. 2013;53(12):1125-36.

[14]. Ogunbodede EO. HIV/AIDS situation in Africa. International dental journal. 2004;54(6 Suppl 1):352-60.

[15]. Kalra S, Grimer RJ, Spooner D, Carter SR, Tillman RM, Abudu A. Radiation-induced sarcomas of bone: factors that affect outcome. The Journal of bone and joint surgery British volume. 2007;89(6):808-13. 
[16]. Birch JM, Alston RD, Kelsey AM, Quinn MJ, Babb P, McNally RJ. Classification and incidence of cancers in adolescents and young adults in England 1979-1997. British journal of cancer. 2002;87(11):1267-74.

[17]. Arora RS, Alston RD, Eden TO, Geraci M, Birch JM. The contrasting age-incidence patterns of bone tumours in teenagers and young adults: Implications for aetiology. International journal of cancer Journal international du cancer. 2012;131(7):1678-85.

[18]. Conforti R, Galasso R, Marrone V, Urciuoli L, Cirillo S. Paget's Disease. A Case Report. The neuroradiology journal. 2012;25(4):475-80.

[19]. Okpokowuruk FS, Oloyede I. Congenital Ewing's Sarcoma in a neonate in Uyo--a case report. The Pan African medical journal. 2013;15:90

[20]. Gouin F, Dumaine V, French S, Bone Tumor Study Groups G-G. Local recurrence after curettage treatment of giant cell tumors in peripheral bones: retrospective study by the GSF-GETO (French Sarcoma and Bone Tumor Study Groups). Orthopaedics \& traumatology, surgery \& research : OTSR. 2013;99(6 Suppl):S313-8. 